\section{References}

1. Alexander K, Ansstrom K, Muhlbaier LH, Grosswald RD, Smith PK, Jones RH, et al. Outcomes of cardiac surgery in patients age $>80$ years: results from the National Cardiovascular network. J Am Coll Cardiol. 2000;35:731-8.
2. Cribier A, Etchaninoff H, Bash A, Borrenstein N, Tron C, Bauer F, et al. Percutaneous trans-catheter implantation of an aortic valve prosthesis for calcific aortic stenosis; first human case description. Circulation. 2002;106:3006-8.

3. Webb JG, Chandavimol M, Ricci DR, Carere RG, Thompson CR, Munt $\mathrm{BI}$, et al. Percutaneous aortic valve implantation retrograde from the femoral artery. Circulation. 2006;113:842-50.

\title{
Nourishing vascularization of a thymoma issued from a left internal thoracic artery graft
}

\author{
Pascal A. Thomas, MD, Frédéric Collart, MD, Christophe Doddoli, MD, Vlad Gariboldi, MD,
} and Guy Moulin, MD, Marseille, France

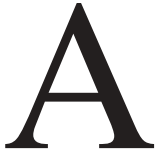

71-year-old man underwent chest computed tomographic (CT) scan in June 2002 as part of an ongoing program for thoracic malignancy screening because he was a former worker with significant exposure to asbestos. In 1988, he had received one left internal thoracic artery (LITA) graft to the mid left anterior descending artery and one saphenous vein graft to the first marginal branch of the left circumflex artery because of severe angina. The chest CT scan identified a $5-\mathrm{cm}$ homogeneous anterior mediastinal mass located on the left aspect of the thymic area (Figure 1). The LITA graft was shown as contiguous with the tumor. Selective catheterization of the LITA disclosed a patent graft as well as a rich, nourishing vasculature supplying the tumor and originating from the graft (Figure 2). Coronary arteriography revealed severe native vessel disease with complete occlusion of the right and $70 \%$ obstruction of the distal left main coronary arteries. Left ventriculography showed no wall motion abnormalities and an ejection fraction of $60 \%$. The patient underwent percutaneous transluminal left main coronary angioplasty with stent placement on July 2002, followed by a 60-day course of clopidogrel with aspirin, subsequently relieved with daily subcutaneous injections of enoxaparin. In October 2002, the patient was operated on through a left lateral thoracotomy. The tumor was adherent to the pericardium and the LITA graft. It was carefully freed from the graft with elective control of all collateral microvessels by bipolar electrocoagulation forceps, division of the thymic veins draining into the innominate vein, and establishment of the

From the Departments of Thoracic Surgery, Cardiac Surgery, and Radiology, Sainte Marguerite \& La Timone University Hospitals, Marseille, France.

Received for publication Nov 22, 2005; accepted for publication Dec 16, 2005.

Address for reprints: P. Thomas, MD, Department of Thoracic Surgery, Ste Marguerite Hospital—CHU Sud, 270 Bd Ste Marguerite, 13274 Marseille Cedex 9, France (E-mail: Pascal-alexandre.Thomas@mail.ap-hm.fr).

J Thorac Cardiovasc Surg 2006;131:1196-7

$0022-5223 / \$ 32.00$

Copyright $\odot 2006$ by The American Association for Thoracic Surgery doi:10.1016/j.jtcvs.2005.12.031

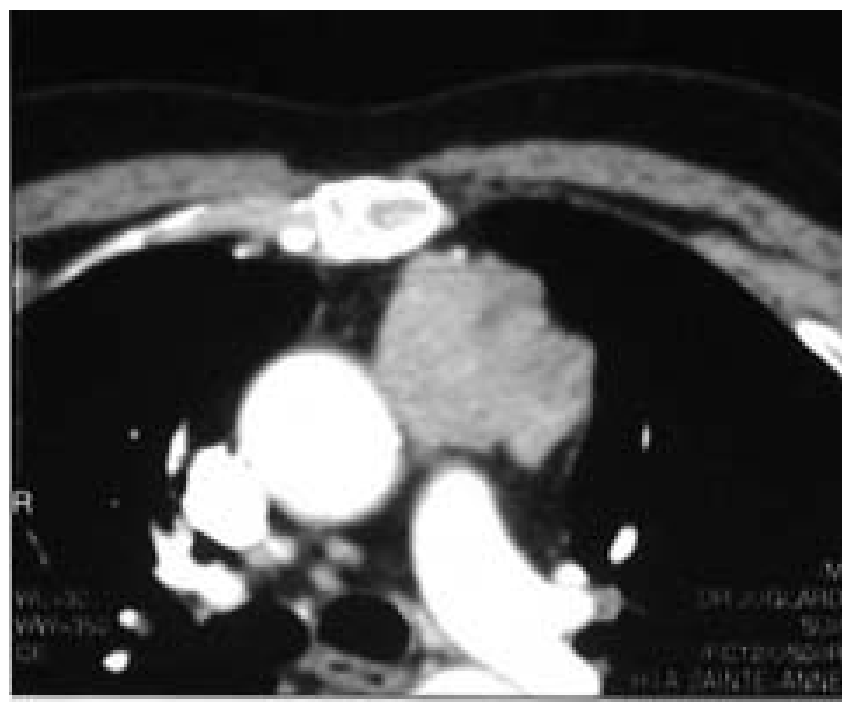

Figure 1. CT scan of the chest showing an anterior mediastinal mass and the LITA graft as an adjacent contrast-enhanced vessel along its anterior aspect.

lateral margin of resection just anterior to the left phrenic nerve. The patient made an uneventful recovery and was discharged on day 11.

Pathologic examination revealed a mixed thymoma according to the Müller-Hermelink classification, with focal invasion of the capsule. The patient was given adjuvant radiotherapy to the mediastinum (50 Gy in 25 fractions). He remains free from recurrence and angina 3 years after the operation.

\section{Discussion}

Surgery remains the standard of care for encapsulated thymomas, with high cure rates anticipated. Thymomas are the most common thymic tumor in adults, usually with an indolent growth pattern. Understandably, the fortuitous discovery of a thymoma during a 


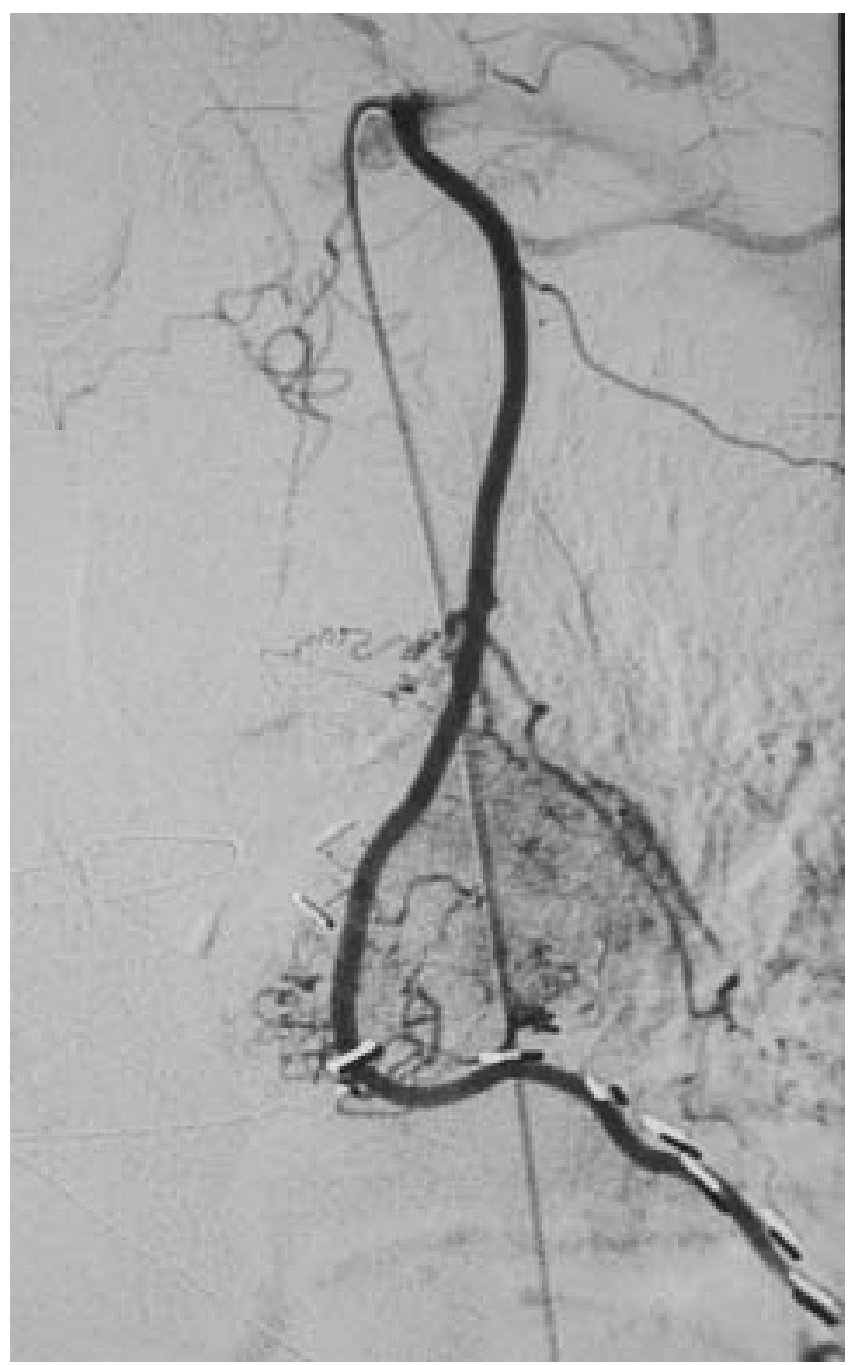

Figure 2. Angiogram of the LITA-to-left anterior descending artery graft showing a rich web of tortuous vessels originating from the arterial graft and irrigating the tumor.

cardiac operation performed through a midline sternotomy is not a rare event. ${ }^{1}$ Although entrapment of a coronary vein graft by a thymoma has been described, ${ }^{2}$ to the best of our knowledge, there have been no reports of tumoral vascularization originating from coronary artery bypass grafts.

The thymus gland consists of two flattened lobes irrigated by the thymic arteries, usually arising from the anterior mediastinal branches of the internal thoracic arteries, ${ }^{3}$ which are otherwise frequently used for elective coronary artery bypass procedures. Since these branches are disconnected de facto at the time of LITA harvesting, the present case strongly suggests that the tumor triggered a local angiogenesis.

The proximity of the tumor and the LITA graft dictated the workup and therapeutic strategy. Chest CT scan provided sufficient grounds to predict the encapsulated nature of the tumor and the absence of infiltration of the LITA graft. Selective catheterization of the LITA was initially attempted to prove the patency of the graft and disclosed that a tumoral neovasculature issued from the graft. Percutaneous transluminal angioplasty of the native coronary vessels was then considered to optimize the myocardial vascularization in case of injury to the patent LITA graft at operation. We chose a left thoracotomy because this approach allows the surgeon to avoid the adhesions that make a redo sternotomy potentially dangerous when patent grafts are present. Moreover, in the present case, the tumor appeared overtly developed toward the left aspect of the pleural cavity and was thus easily accessible via a lateral approach. Intraoperatively, a meticulous control of all collateral microvessels was performed with bipolar electrocoagulation forceps to limit the morphologic changes that monopolar thermocoagulation would have produced in the wall of the graft. The patient received radiotherapy because it is strongly recommended in all patients with completely resected thymomas when tumor extension beyond the capsule is documented pathologically. ${ }^{4}$ Although the use of the LITA in myocardial revascularization after mediastinal irradiation has been regularly reported, there is no extensively available data about safety of mediastinal radiotherapy in patients with a remote history of coronary artery bypass surgery.

In conclusion, the favorable outcome achieved in this case was due to a tailored strategy having included (1) preoperative LITA angiography, (2) preoperative coronary angiography with percutaneous transluminal angioplasty of the native vessels, (3) choice of the left thoracotomy, and (4) adjuvant radiotherapy.

\section{References}

1. Mirsadraee S, Shah SS, Kumar B, Kaul P. Incidental locally infiltrating malignant thymoma and coronary artery bypass surgery: excision should always be considered. J Card Surg. 2005;20:291-2.

2. Jaklitsch MT, Byrne JG, Mery C. Thymoma encasing last patent vein graft to the heart. J Thorac Cardiovasc Surg. 1999;118:561-3.

3. Bell RH, Knapp BI, Anson BJ, Larson SJ. Form, size, blood supply and relations of the adult thymus. $Q$ Bull Northwest Univ Med Sch. 1954; 28:156-64.

4. Thomas CR, Wright CD, Loehrer PJ. Thymoma: state of the art. J Clin Oncol. 1999;17:2280-9. 